\title{
Octyl Phenol Synthesis Using Natural Clays
}

\author{
S. Casuscelli, E. Herrero, J. Fernandez and M. Piqueras \\ CITeQ, Universidad Tecnológica Nacional, Facultad Regional Córdoba, C.C.36, 5016 Córdoba, Ar- \\ gentina
}

Tel/Fax: 0351-4690585, E-mail: sandra@sa.frc.utn.edu.ar

\begin{abstract}
A series of clay minerals, HB, NB and Al-PILC have been studied in the alkylation reactions of 2-octanol with phenol at $180^{\circ} \mathrm{C}$, under conditions of alcohol/phenol = 1 (mole ratio) and $\mathrm{W} / \mathrm{F}_{\mathrm{A}}{ }^{\mathrm{o}} \circ=64,27 \mathrm{ghmol}^{-1}$. The selectivity of Al-PILC was $77,12 \%$ for octyl phenol and $16,5 \%$ for dioctyl phenol.
\end{abstract}

\section{Introduction}

The aromatic alkylation is an interesting industrial reaction catalyzed by acids. Octylphenoles, can be obtained by alkylation of phenol with the corresponding olefin or alcohol. These chemicals are used as surfactants.

Generally these products are synthesized using catalysts such as: sulphuric acid, boron trifluoride, hydrofluoric acid and phosphoric acid, with all the involved environmental pollution problems.

In this paper are shown the results obtained when the traditional catalysts are replaced by a heterogeneous acid catalysts, obtained from natural clays, in order to decrease the environmental pollution.

\section{Experimental}

The catalysts were prepared starting from a natural bentonite, NB, and HB means a bentonite treated with hydrochloric acid according to [1], AL-PILC 10 to a bentonite pillared with an oligomer of $\mathrm{Al}$ (10 mmoles $\mathrm{Al} / \mathrm{g}$ of bentonite) according to [2]. The catalysts were characterized by surface areas: $\mathrm{NB}=44 \mathrm{~m}^{2} / \mathrm{g} ; \mathrm{HB}=64 \mathrm{~m}^{2} / \mathrm{g}$ and $\mathrm{AL}-\mathrm{PILC}=211 \mathrm{~m}^{2} / \mathrm{g}$.

The reactions were carried out at room pressure in a fixed bed reactor, using $0,5 \mathrm{~g}$ of catalysts under isothermic conditions, a mixture of phenol (Merck, 99.3\%) and 2-octanol (molecular rate 1/1) was injected, preheated and diluted with a flow of dry nitrogen; the products and unreacted reagents were collected at $273^{\circ} \mathrm{K}$ and analyzed by GLC using a column of OV-101 (10\%). The reaction products were identified by GC- mass, FT-IR and ${ }^{1} \mathrm{H}$ NMR. The conversion and selectivities are in moles per cent. 


\section{Results and Discussion}

Phenol conversion and products selectivity at time on strem 2 hours, are shown in the next table.

\begin{tabular}{|c|c|c|c|c|c|}
\hline \multirow{2}{*}{ CATALYSTS } & PHENOL & \multicolumn{4}{|c|}{ SELECTIVITY } \\
\cline { 3 - 6 } & CONVERSION & Alkylphenol & $\begin{array}{c}\text { Dialkylphe- } \\
\text { nol }\end{array}$ & $\begin{array}{c}\text { Trialkylphe- } \\
\text { nol }\end{array}$ & Ether \\
\hline NB & 4.48 & 56.93 & 2.38 & 0 & 40.68 \\
\hline HB & 29.92 & 63.42 & 28.83 & 6.33 & 0 \\
\hline Al-PILC 10 & 35.50 & 77.12 & 16.65 & 5.97 & 0.25 \\
\hline
\end{tabular}

We can observe that the increase in conversion correlates with the acidity of the solids; NB show a low acidity owing to terminal silanole groups. The acid treatment and the pillaring increase the acidity, the phenol conversion and the selectivity to the alkylation products.

Acknowledgements: The authors are grateful to Guillermo Ghione for the experimental collaboration and to the CONICOR for the economic aid AIF NO 4425/97 and 4701/99.

\section{References and Notes}

1. Orio, O.A.; Herrero, E.R.; Pérez, C.F.; López, A.F.; Anunziata, O.A. An. Asoc. Quim. Argent. 1984, 72, 483.

2. Herrero, E.R.; Bonetto, L.D.; Orio, O.A.; Mendiondo, H.; Cortés, M.V.; Russo, R. Actas XII Simp. Ib. de Catal. 1990, 3, 406. 